\title{
Los periodistas y su responsabilidad en la incorporación de préstamos en español
}

\author{
Constanza Gerding Salas* \\ Antena Chilena de Neología, Universidad de Concepción, Chile \\ Paola Cañete-González** \\ Antena Chilena de Neología, Universidad de Concepción, Chile \\ Carolin Adam*** \\ Antena Chilena de Neología, Universidad de Concepción, Chile \\ Oscar Elías Blanco Correa**** \\ Antena Chilena de Neología, Universidad de Concepción, Chile
}

\section{Resumen}

Teniendo en consideración que los préstamos son la segunda forma más frecuente de innovación léxica en español y que estos se manifiestan en la prensa escrita, se estimó pertinente consultar a periodistas sobre su participación en la incorporación de voces extranjeras y las motivaciones que los incitaban a emplearlas.

\footnotetext{
* Para correspondencia, dirigirse a: Constanza Gerding Salas (cgerding@udec.cl), Casilla 160-C, Correo 3, Concepción, Chile.

** Para correspondencia, dirigirse a: Paola Cañete González (pcanete@udec.cl), Casilla 160-C, Correo 3, Concepción, Chile.

*** Para correspondencia, dirigirse a: Carolin Adam (cadam@udec.cl), Casilla 160-C, Correo 3, Concepción, Chile.

**** Para correspondencia, dirigirse a: Oscar Elías Blanco Correa (oscareliablanco@ udec.cl), Casilla 160-C, Correo 3, Concepción, Chile.
} 
Para este propósito, se aplicó una encuesta por correo electrónico a profesionales de la prensa mediante un instrumento que incluía preguntas acerca de los motivos de uso de préstamos, la pertinencia de estos motivos, las secciones del periódico más prolíferas en cuanto al uso de préstamos y la importancia autoatribuida de los periodistas en la incorporación de unidades léxicas extranjeras en la redacción de noticias. Los resultados arrojaron una gran variedad de motivaciones, entre las que destacan el llenado de vacíos léxico-culturales y el uso extendido de préstamos. Los periodistas refirieron que intentaban evitar el uso de préstamos y que las secciones en que usaban estas voces con mayor frecuencia eran Ciencia y Tecnología, Economía e Internacional. También se determinó que los periodistas atribuían una gran importancia a sus propias decisiones con respecto al uso y al no uso de préstamos en sus escritos.

Palabras clave: periodista, préstamo lingüístico, motivo de uso, cuestionario.

\title{
JOURNALISTS AND THEIR RESPONSIBILITY TO INCORPORATE LOANWORDS INTO SPANISH
}

\begin{abstract}
Bearing in mind that loanwords are the second most frequent form of lexical innovation in Spanish and that there is plenty of evidence of these new words in the written press, a survey was carried out among journalists to inquire about their participation in the adoption of foreign words and the motivations they claimed for using them. In order to achieve this goal, journalists were asked about the reasons they had for using loanwords and how relevant they thought these reasons were, their self-attributed importance in the incorporation of foreign words into journalistic texts, and the most prolific newspaper sections in terms of loanword use. According to the results, a wide variety of motivations, which included filling lexical-cultural gaps and the widespread use of loanwords, were determined. Journalists reported that they tended to avoid using loanwords and that the sections in which they used these lexical items most frequently were Science and Technology, Economics and International. The fact that journalists attached great importance to their own decisions regarding the use or non-use of loanwords in the press was also determined.
\end{abstract}

Keywords: journalist, loanword, reason for use, questionnaire.

Recibido: $17 / 12 / 18$

Aceptado: 14/01/19 


\section{INTRODUCCIÓN ${ }^{1}$}

\subsection{ForMACIÓN DE PERIODISTAS Y NEOLOGÍA LÉXICA}

El periodismo se inició como profesión universitaria en Chile en la década de 1950, cuando se fundó en la Universidad de Chile la primera Escuela de Periodismo (González Rodríguez 2003; Zerán Chelech 2003). Con anterioridad, se ejercía como oficio libre, con periodistas que se formaban en las salas de prensa de periódicos o radioemisoras y 'en terreno' (Mellado Ruiz y Del Valle Rojas 2008). En 1956 (Ley N 12.045), se estableció que para desempeñar dicha profesión era necesario poseer el título universitario o la inscripción en el registro de la Orden (Cea Egaña 1985). Más tarde, dicha ley fue objeto de modificaciones que hoy permiten que expertos en determinadas materias puedan opinar, relatar, informar o comentar aspectos de su interés por cualquier medio de comunicación social.

Ahora bien, actualmente los planes de estudio de las carreras de periodismo de universidades tanto públicas como privadas de Chile incluyen una formación fundamental en lo que respecta a la comunicación oral y escrita a través de asignaturas como redacción periodística o producción de textos (ver, por ejemplo, las universidades de Chile, de Concepción, de La Serena, Católica de Valparaíso, Austral de Chile o Adolfo Ibáñez). En la formación de los periodistas también se contempla el inglés como lengua extranjera o como lengua para fines específicos, aunque en algunos casos las carreras no dictan la asignatura, sino solo la exigen como requisito de egreso. Por otro lado, no se observa en su formación una línea destinada específicamente a la adquisición y el uso del léxico del español, lo que hace presumir que esta se aborda desde otras asignaturas de Comunicación. La formación lingüística previamente descrita lleva a preguntarse, en general, acerca del uso del léxico y, en particular, del empleo de préstamos por parte de los periodistas, aspectos que se abordan en la presente investigación.

El léxico es definido por Chela-Flores (1998) como el cúmulo de experiencia por el cual se manifiesta la forma de pensar, sentir y actuar de un grupo de habla. Su originalidad, particularidad y dinamismo propicia los cambios que operan en una lengua en un espacio de tiempo determinado. Dichos cambios se reflejan en los neologismos, que amplían, designan o

\footnotetext{
Proyecto de Investigación, código 03.F5.01 de la Vicerrectoría de Investigación de la Universidad de Concepción, Chile.
} 
significan nuevas realidades derivadas de los usos y transformaciones de la lengua, como consecuencia de las actividades humanas, lo que permite su renovación y revitalización (Otaola Olano 2004). Entre estas unidades neológicas, los préstamos lingüísticos son uno de los tipos más productivos de neologismos en el español actual (Fuentes, Gerding, Pecchi, Kotz y Cañete 2009).

$\mathrm{Si}$ bien es cierto que todas las lenguas absorben permanentemente vocablos de otras y los acomodan a su propia idiosincrasia, para algunos lingüistas no siempre existe claridad con respecto a la conciencia que puedan tener los periodistas acerca de la responsabilidad que les cabe en el empleo y la propagación de estos ítems léxicos, especialmente en lo que se refiere a los préstamos anglicados, de uso extendido en la variedad chilena del español actual (Gerding-Salas, Fuentes, Gómez y Kotz 2012, Gerding Salas, Cañete González y Adam 2018). La Real Academia Española se limita a señalar si existe o no justificación para el uso de un extranjerismo en español y a recomendar, si se da el caso, el uso de equivalencias o adaptaciones. A su vez, plantea que estos no son unidades rechazables en sí mismas, pero sugiere "que su incorporación responda en lo posible a nuevas necesidades expresivas y, sobre todo, que se haga de forma ordenada y unitaria, acomodándolos al máximo a los rasgos gráficos y morfológicos propios del español" (Real Academia Española 2018: §1). Además indica que, cuando se trata de préstamos que por uso internacional se hayan incorporado en su forma original (ballet, blues, jazz o software), lo adecuado es advertir al lector de su condición marcándolos con letra cursiva o con comillas para señalar su carácter de unidad ajena al español.

Si bien la Real Academia Española entrega algunas normas sobre el uso de estas unidades, institucionalmente los profesionales de la prensa suelen obtener orientación lingüística y estilística a partir de cuerpos normativos llamados manuales, guías o libros de estilo, obras de consulta propias de cada medio periodístico, que permiten unificar criterios de redacción y de uso y responder al carácter propio de un medio en particular. Uno de los aspectos abordados en los manuales de estilo es el tratamiento que los redactores deben dar a los neologismos, en general, y a los préstamos, en particular (Pérez Lagos y Guerrero Ramos 2005). En algunos países, la consulta de libros de estilo de los periódicos es de libre acceso (por ejemplo, Clarín, de Argentina y El País, de España); en Chile, en cambio, resulta difícil acceder a estos cuerpos normativos. 


\subsection{NeOlogía Y NEOLOGismo}

El estudio del surgimiento de nuevas palabras es abordado por la neología léxica, uno de los tantos campos de la lingüística actual (Esteban Asencio 2008). Rondeau (1983) afirma que la innovación se relaciona con el dinamismo de las lenguas vivas, a pesar de la impresión de estabilidad que los hablantes puedan tener de ellas. De esta forma, la neología evidencia cómo las lenguas incorporan constantemente nuevas voces a su repertorio, lo que, unido a otros rasgos, constituye un indicador manifiesto de su vitalidad.

En este orden de ideas, Otaola Olano (2004) afirma que el neologismo es una lexía nueva en cuanto a forma y sentido, ya sea en el interior de la misma lengua o bien proveniente de otra. Esta idea es compartida por Alcoba Rueda (2007), quien afirma que el neologismo es una palabra o frase enteramente nueva (en cuanto a forma y significado) o parcialmente nueva (por la incorporación de un significado o acepción) de las que el hablante dispone en las diversas situaciones comunicativas para designar y describir objetos, situaciones o procesos desconocidos.

En cuanto a la forma de abordarlos, se han creado diversas taxonomías (por ejemplo, Rondeau 1983; Cabré 1989; Llopart y Freixa 2014), que permiten estudiar los neologismos desde distintas perspectivas. En este trabajo se emplea la propuesta del Observatori de Neologia (2004), según la cual los neologismos se clasifican en tres categorías: de forma, de sentido y préstamos. De ellas, el presente trabajo estudia los préstamos, y el propósito es indagar acerca de su uso en la prensa y el papel que puedan desempeñar los periodistas en la introducción y la difusión de estas unidades léxicas.

\subsection{PRÉSTAMOS Lingǘ́sticos}

Los préstamos lingüísticos son aquellas voces provenientes de una lengua extranjera, que se incorporan a una lengua receptora para designar hechos, conceptos, procesos, etc. La mayoría de las veces, esta incorporación enriquece y dinamiza la lengua que los adquiere. Para Martínez Otero (1959: 189), el préstamo lingüístico es "todo elemento tomado de otra", incluidos los elementos tomados de dialectos de la misma nación. Al ser los préstamos lingüísticos una adquisición proveniente de otra lengua, su incorporación a la lengua receptora se puede dar por calcos o por préstamos semánticos o fonológicos (Otaola Olano 2004). Además, estas unidades pueden ser adaptadas o no adaptadas (Observatori de Neologia 2004). 
Los motivos por los que aparecen los préstamos son variados. Seco (2000: 256), por ejemplo, menciona diferentes tipos de necesidades a las que responde la entrada de estas unidades en una lengua y señala que estos tipos pueden combinarse. Por una parte, "hay que designar una cosa nueva que viene de afuera y que aún no tiene otro nombre que el que ya trae puesto"; por otra parte, ese algo ya tiene su denominación en un idioma, pero el hablante la ignora, o, aunque la conozca, prefiere la extranjera. A su vez, el autor señala que esta preferencia obedece también a alguna necesidad, como la de la economía y la comodidad (tal es el caso de clip frente a sujetapapeles); o la de la atracción de lo nuevo, que reclama decorar el propio discurso con alguna voz "de vanguardia" (por ejemplo, glamour); o la del énfasis (como en building); o la del eufemismo (el caso de call girl); o la de la expresión de un matiz o una precisión que no dispone en nuestra lengua de etiqueta propia (por ejemplo, stick, en golf, frente a palo) (Seco 2000: 257).

Además de las ya mencionadas, existen otras razones que pueden explicar la incorporación de préstamos en la lengua: la intención de obtener un mayor grado de información, claridad, variación, economía y precisión en lo que se expresa (González y Rodríguez 2011; Diéguez 2005); la intención de dar al discurso un "estilo moderno, fresco, novedoso, original e internacional, además de enfatizar lo dicho y presentar la información de una forma amena" (Estornell Pons 2012: 64); o también el hecho de que la unidad extranjera ya esté instaurada en la lengua (Estornell Pons 2012).

Ahora bien, estudios anteriores (Ortega Martín 2001; Morin 2006; Esteban Asencio 2008; Guerrero Ramos 2013; Gerding et al. 2014, Gerding et al. 2018) han determinado que la mayoría de los préstamos en uso en el español se incorpora desde el inglés, debido a que este es el idioma vehicular del mundo globalizado de hoy relacionado con Estados Unidos, potencia mundial a nivel tecnológico y económico (Briceño Ruiz 2006; Bernal-Meza 2008).

Así, para Vélez Barreiro (2003), los préstamos del inglés, también llamados anglicismos, son unidades léxicas o fraseológicas, en cuanto a significante y significado o a al menos uno de los dos, provenientes del inglés. De igual modo, Pratt (1980), citado por Barbero Andrés (2010), indica que el anglicismo es un elemento lingüístico del modelo inglés que se emplea en español.

Entre las razones de uso de los anglicismos se mencionan la rapidez con la que se realiza el trabajo en la redacción de un periódico, lo que provoca que se termine utilizando el inglés para formular algo que podría expresarse con recursos propios del español, ya que la mayor parte de la información proviene de fuentes anglosajonas (Vélez Barreiro 2003); el interés del redactor por dar muestras de dominio o conocimiento del tema sobre el que 
está escribiendo, por lo que incluye algún término técnico en lengua inglesa $\mathrm{o}$, por ejemplo, en el área de la economía, porque la denominación de un proceso o concepto extranjero no cuenta con un término equivalente en español (Vélez Barreiro 2003); la contribución a la economía de la expresión debido a que el inglés tiende al uso de monosílabos y términos compuestos (Diéguez 2004); y, por último, la intención de dar variedad a la expresión al alternar el uso del anglicismo y su equivalente, alternancia que contribuye a la cohesión léxica del texto en la medida en que los anglicismos se emplean como mecanismos de reiteración (Diéguez 2004).

Por su parte, Gerding, Fuentes y Kotz (2012) sugieren cuatro factores que determinarían el uso de préstamos anglicados, ya sea por necesidad designativa o estilística: vacío denominativo, prestigio social, economía lingüística y preferencia de los usuarios. González (2003), citando a Anttila (1989), sostiene que la necesidad denominativa es la causa más común y que el prestigio parece ser el factor más importante a la hora de decidir qué tipo de vocabulario toma en préstamo una lengua. A partir de esta observación, la autora clasifica los anglicismos en 'necesarios' e 'innecesarios', siendo estos últimos los que se usan a pesar de la existencia de una palabra alternativa en español, debido precisamente a que están determinados por factores como el prestigio o esnobismo que a veces rigen la interacción social de los hablantes.

Guerrero Ramos (2010: 37) se refiere a ellos como préstamos 'por necesidad o denotativos', por una parte, y préstamos 'de lujo o connotativos', por otra, y plantea que los primeros "sirven para designar productos y conceptos nacidos en un país extranjero", mientras que los segundos "son aquellos causados por un mimetismo lingüístico, desarrollado por el prestigio ejercido por un cierto tipo de civilización y de cultura, o por ignorancia, papanatismo, etc.”.

Los diversos motivos que inducen al uso de préstamos se ven reflejados en los textos tanto orales como escritos. En tal sentido, como sostiene Perdiguero (2003), uno de los observatorios más eficaces para detectar la aparición de palabras nuevas en la lengua es la prensa.

\subsection{Préstamo LINGÜÍSTICO Y PRENSA ESCRITA}

Méndez (2011a) señala que el estilo periodístico es una mezcla de géneros que da como resultado un lenguaje complejo y con diversas características difíciles de describir de manera general. Esta diversidad de géneros se refleja en las distintas secciones que componen un periódico, cada una con un lenguaje particular, referida a un área de especialidad determinada. A la vez, 
se observan diferencias con respecto al uso de neologismos, ya que algunas secciones presentan un mayor número de unidades neológicas que otras.

Con respecto a la incorporación de préstamos del inglés en la prensa escrita, Sáez Godoy (2005), por ejemplo, llegó a la conclusión de que la presencia de anglicismos es particularmente fuerte en áreas como economía, deportes, comercio, ciencias, tecnología, comunicaciones, turismo, espectáculos, música y moda, debido a que son ámbitos del saber en los que se requiere un vocabulario más especializado. Las indagaciones de Delgado Álvarez (2005), quien estudió la presencia de anglicismos en la prensa costarricense, apuntan a un resultado similar, ya que pudo constatar que las secciones del diario analizado donde observó la mayor presencia de anglicismos fueron Espectáculos, Sociedad, Deportes, Nacionales, Economía y, en menor medida, las de Opinión e Internacionales.

Debido a la importancia de los anglicismos en la prensa escrita de todos los países que forman parte de la red Antenas Neológicas, la AChN-UdeC ha examinado la presencia de voces anglicadas en la prensa chilena en distintas áreas del conocimiento (Gerding y Fuentes 2011; Gerding, Fuentes, Gómez y Kotz 2012; Gerding et al. 2012; Gerding et al. 2014; Gerding et al. 2018). Según Sáiz Martínez (2011), Chile es un país muy receptivo frente a la influencia anglosajona, particularmente en el ámbito de la economía. Esta situación fue confirmada por un estudio de la AChN-UdeC (Gerding, et al. 2012), que comprobó que más del $60 \%$ de los anglicismos no adaptados se concentraban en cuatro áreas del conocimiento: a) tecnologías de la información y computación, b) cultura y entretención, c) deportes y d) economía, comercio y finanzas. Según estas autoras, la fuerte presencia de anglicismos en estos cuatro ámbitos se debe, posiblemente, a un desarrollo disciplinar veloz que hace necesario llenar vacíos léxicos (ciencias y computación), al éxito de manifestaciones culturales estadounidenses en Chile, sobre todo entre los jóvenes (cultura y entretención), al consumo de deportes de masas y la adopción de su jerga (deportes), y a la introducción, en los años 80 del siglo XX, de un modelo económico basado en la doctrina de libre mercado proveniente de Estados Unidos (economía, comercio y finanzas).

En este marco, y para ampliar el espectro de estudio sobre el uso de los préstamos neológicos, se ha contemplado en el presente trabajo indagar acerca de la percepción, opinión y creencias que poseen los periodistas sobre el empleo de los préstamos lingüísticos, los motivos de su uso, en general, y la pertinencia de estos, y los motivos de su empleo en las distintas secciones del periódico, en particular, además de la importancia del rol que el periodista se asigna en la incorporación de estas unidades en el español. 


\section{METODOLOGÍA}

Con el fin de conocer la postura de periodistas con respecto al uso de préstamos en español, se diseñó un conjunto de preguntas que se administró a través de un cuestionario electrónico, ya que éste es una herramienta que permite llegar a un gran número de informantes $\mathrm{y}$, a la vez, es útil para aquéllos que cuentan con poco tiempo y que desean colaborar con una investigación determinada. Para la elaboración de este cuestionario, se utilizó la versión básica de la plataforma Survey Monkey® (2017), que ofrece distintas opciones, de las cuales se optó por el cuestionario semiestructurado, que consta de dos tipos de interrogantes: preguntas de respuesta cerrada, que pueden ser dicotómicas, categorizadas o de valoración, y preguntas de respuesta abierta. La ventaja de este tipo de cuestionario sobre el instrumento de tipo estructurado es que da a los informantes la posibilidad de contestar algunas preguntas de forma más flexible y espontánea.

La muestra estuvo constituida por periodistas en ejercicio de la profesión en diversos ámbitos, a saber: prensa, departamentos de comunicaciones en empresas públicas y privadas, instituciones de enseñanza superior para la formación de periodistas, por nombrar las más relevantes. Se envió el cuestionario vía correo electrónico de forma directa o a través de contactos (por ejemplo, jefes de prensa) a varios centenares de potenciales informantes; sin embargo, solo se obtuvo respuesta de 52 periodistas.

El cuestionario constó de dos partes: una de información personal general sobre el periodista-informante anónimo, como edad, género, ámbito de desempeño laboral, especialidad en la que ejercía y años de experiencia laboral, y la otra consistió en 14 preguntas relacionadas específicamente con el uso de préstamos en el ejercicio del periodismo. Para este trabajo se seleccionaron las preguntas que decían relación con los motivos de uso o no uso de préstamos, la pertinencia de estos motivos, las secciones del diario en las que los préstamos aparecen con mayor frecuencia, los motivos de uso de estas unidades léxicas en dichas secciones y la importancia autoatribuida del rol del periodista en la incorporación de préstamos en el español.

Con las respuestas entregadas por los informantes se realizaron diversos análisis cualitativos. En los casos en que hubo múltiples respuestas, se decidió organizarlas en categorías establecidas por los investigadores, de acuerdo a su naturaleza, de forma que sintetizaran la coincidencia de los datos entregado por los encuestados.

En la pregunta relacionada con los motivos de uso de préstamos, se clasificaron las respuestas en dos categorías: razones de uso de palabras de otras lenguas en el lenguaje periodístico y razones de no uso de estas 
palabras. A su vez, las respuestas obtenidas en ambas categorías se agruparon en distintos campos. Por ejemplo, las respuestas "recoge el verdadero sentido del término" y "porque la especialidad lo requiere" pertenecen al campo 'exigencia terminológica'. De esta manera, se obtuvo un total de 11 campos: 'exigencia terminológica', 'llenado un vacío léxico o cultural', 'uso extendido del préstamo', 'políticas del medio', 'valoración por lo extranjero', 'razones estilísticas y de comunicación', 'normativa lingüística', 'uso innecesario', 'valoración de la lengua materna', 'prejuicio hacia el lector' y 'no da razones'.

De igual modo, en la pregunta relacionada con los motivos de uso en función de las secciones del periódico se establecieron cinco categorías: 'uso extendido', 'razones estilísticas y de comunicación', 'exigencia terminológica', 'políticas y normativas' y 'otros'. A su vez, estas fueron organizadas en distintas subcategorías, tales como economía lingüística, registro, énfasis, premura al redactar, entre otras. Una vez establecidas, se las vinculó con las secciones del periódico en que se veían reflejadas con mayor frecuencia.

Para las demás preguntas, el procedimiento de análisis se explica brevemente en cada subcategoría de respuestas en el apartado de resultados correspondiente. La pertinencia de los motivos por los que el periodista utiliza préstamos en sus textos se midió a través de una escala de Lickert con cinco opciones que iban desde 'nada pertinente' hasta 'totalmente pertinente'. De la misma manera se midió la responsabilidad atribuida por estos profesionales en la incorporación de préstamos en la lengua, con cinco opciones que iban desde 'ninguna importancia' hasta 'muchísima importancia'. Por último, para identificar las secciones del periódico con mayor abundancia de préstamos, se entregó una lista de cotejo en la que debían marcar hasta cinco opciones, con una opción de respuesta abierta.

\section{RESULTADOS}

De acuerdo con Hurtado González (2001), los periodistas suelen ser hablantes de calidad, con una sólida formación y competencia lingüísticas que, además, poseen en su mente una teoría del lenguaje que se evidenciaría en sus textos. Posiblemente, estas particularidades permitan entender las decisiones que ellos toman con respecto al uso o no uso de préstamos lingüísticos en sus reseñas noticiosas. De allí que se consultó a los informantes sobre los motivos que los inducen a tomar estas decisiones y sus respuestas fueron agrupadas en razones por las que usan préstamos y razones por las que no los usan. 
El motivo más frecuente del primer grupo corresponde a 'llenar un vacío léxico o cultural'. Esta respuesta se refiere al uso de aquellas voces de origen extranjero que son usadas por los hablantes cuando en la lengua receptora no existe un equivalente para dar cuenta de la realidad. Dicho uso ocurre con frecuencia en la lengua general, pero también se presenta en ámbitos especializados, principalmente en el lenguaje escrito, en el que su uso sería menos frecuente (Fischer 2008, citado por Bouwman 2017); por ejemplo: benchmark, commodities, venture capital (economía), fixture, hard tag, wetware (tecnología), backflip, furlong (deportes).

Además del uso del préstamo por la falta de un equivalente en español, el intento de construir realidad con la noticia se convierte en un fuerte motivo para el empleo de dicho fenómeno léxico, lo que de algún modo sustenta las afirmaciones de Chumaceiro y Álvarez (2004), quienes han aseverado que el actual español de América es producto de la transculturación lingüística, económica, social, tecnológica, cultural y mediática.

La segunda razón más frecuente corresponde a 'uso extendido del préstamo'. Esta parece encontrar asidero en la influencia que ha tenido la lengua inglesa en la denominación y descripción de situaciones o actividades, lo que permite suponer el encuentro de dos culturas y, por lo tanto, la integración de la lexía a la comunidad de habla, normalmente sin ningún tipo de adaptación ortográfica. En este caso, el periodista cumple la función de reverberador de una voz que se ha instalado en el léxico, ya sea por moda o porque el equivalente en español no es tan común.

Otras razones relacionadas con el uso de préstamos, pero menos frecuentes que las anteriores, son: 'exigencia terminológica', 'razones estilísticas y de comunicación', 'políticas del medio' y 'valoración por lo extranjero'. Con respecto a la primera, se puede inferir que el uso del préstamo lingüístico recoge el "verdadero" sentido del término, ya que responde a la especialidad de la que se escribe (deporte, industria tecnológica, comunicaciones, derechos humanos, entre otras) y, por lo tanto, se requiere su empleo para mantener la fidelidad léxica o terminológica de la noticia reseñada. Efectivamente, los periodistas suelen usar el préstamo lingüístico porque consideran que le da precisión léxica al texto que redactan, debido a que este fenómeno lingüístico responde a un caso de especificidad y de restricción (Bouwman 2017).

En cuanto a las 'razones estilísticas y de comunicación', con el uso del préstamo se intenta enriquecer el texto, además de entregar una redacción más natural y fluida. Desde esta óptica, Hurtado González (2001: 298) señala que el periodista intenta satisfacer el derecho de información de sus lectores, para lo cual es imprescindible que las palabras signifiquen lo que quieren decir. En caso contrario, la lengua no comunica, convirtiéndose 
en un catálogo de lugares comunes, porque basta con repetir las mismas trampas semánticas insistentemente para que éstas acaben por incorporarse a esa galería de tópicos con que se acostumbra describir la realidad para hacerla más tolerable.

De acuerdo con la apreciación anterior, se entiende que el empleo del préstamo lingüístico por parte de los periodistas responde a la exigencia que supone satisfacer al lector. Para tal fin, apela al estilo del discurso y, por tanto, su selección léxica ha de marcar la forma de transmitir la información. Así, el uso del préstamo lingüístico le permite comunicar el mensaje lo más fielmente posible para que no solo cumpla con su función fática y expresiva, sino que también sea aceptada por quienes acceden a la reseña noticiosa.

En cuanto al ítem 'políticas del medio', los periodistas mencionaron que en algunos casos existe presión por parte de las jefaturas de prensa para usar préstamos lingüísticos, debido a que muchos medios suelen estar relacionados con instituciones extranjeras. Por esta razón, el uso de préstamos obedece más a una serie de preceptos de redacción y estilo que a una necesidad. Este hecho llama la atención debido a que, si bien la Real Academia Española regula el empleo de los préstamos lingüísticos, en algunos casos esta normativa es complementaria, ya que diarios como Clarín de Argentina, El Nacional de Venezuela y El País de España poseen su propio manual de estilo.

Por último, en cuanto a la 'valoración por lo extranjero', el periodista suele ser un hablante de su tiempo, y su discurso responde a una época que se apega al gusto por lo foráneo o que se adecua a las normas lingüísticas que suelen instaurar los hablantes comunes. Por esta razón, los periodistas en ocasiones recurren a voces extranjeras para establecer correspondencia con sus lectores. Asimismo, esta afinidad por los usos lingüísticos foráneos propiciaría una imagen de cosmopolitismo. Cabe resaltar que el empleo de un préstamo no es inocente en el lenguaje: se constituye en un arma para retratar una realidad, la forma de pensar y la vorágine del mundo que le ha tocado a quien escribe.

Entre las razones menos frecuentes del uso de los préstamos lingüísticos se encuentra la 'normativa lingüística', lo que posiblemente se explique mediante directrices emanadas de la Real Academia Española (2018), que establece algunas normas sobre el uso de las voces extranjeras cuando éstas responden a un uso internacional, como hardware o blues. Lo anterior permite inferir que el empleo de préstamos lingüísticos por parte de los periodistas se ajusta a dichas normas para mantener la unidad lingüística del español sin menoscabar la influencia de otra lengua.

Y, por último, se debe mencionar que solo un periodista indicó que "no hay razones' para el uso del préstamo lingüístico. Esta respuesta sugiere 
que el empleo de la voz extranjera no remite a una normativa, ni a la falta de un equivalente ni al uso extendido de un préstamo. Aparentemente, en este caso, su uso se circunscribiría a la libertad que tiene el periodista al momento de escribir la reseña noticiosa, por lo que el empleo de la voz extranjera es una opción.

Ahora bien, así como los periodistas esgrimieron motivos para justificar el uso del préstamo lingüístico, existe un grupo que evita su empleo debido a que los considera innecesarios; probablemente, esto se deba a que, como los lectores son hispanohablantes, no requieren la forma extranjera porque posiblemente existe un equivalente en español. Piénsese, por ejemplo, en la voz tour: probablemente, un periodista consideraría que su uso es apropiado porque responde a los tiempos actuales y, a la vez, le daría un aire de cosmopolitismo. No obstante, de acuerdo a la respuesta dada por algunos profesionales de la prensa, el empleo no sería necesario, porque en español existe la voz gira, que se ajustaría a lo que se desea comunicar: los conciertos ofrecidos por un cantante o grupo musical.

La respuesta anterior encuentra correspondencia con el ítem 'valoración de la lengua materna', que da a entender que los periodistas prefieren la voz castiza por su apego a la lengua materna y por el poco interés por emplear voces extranjeras en la redacción de la noticia.

Otros motivos para no usar préstamos lingüísticos se relacionan con 'razones estilísticas y comunicativas' y 'normativa lingüística'. Curiosamente, estas razones también las esgrimieron los periodistas para justificar el uso de préstamos. El primero de estos motivos probablemente obedezca a que el empleo de la voz extranjera no tiene correspondencia con aspectos lingüísticos propios del español, por lo que su uso rompería con el estilo (sintáctico o semántico) al transmitir la información. El segundo motivo podría obedecer a que muchas veces la lengua suele estar asociada con identidad, por lo que emplear un préstamo lingüístico no evidencia la riqueza de la lengua. Esto supone que el periodista, al escribir una noticia en un país hispanohablante, privilegiaría la voz castiza y, para tal fin, asumiría directrices dadas por instituciones normativas como la Real Academia Española o el manual de estilo del medio en el que se desempeña.

Por último, algunos periodistas admitieron no usar préstamos lingüísticos por respeto a las 'políticas del medio' para el que escribían, con lo que se privilegiaría la fidelidad hacia la lengua materna y hacia los usos diatópicos o diastráticos propios de la reseña noticiosa; esto contrasta con lo informado por otros periodistas, que adujeron adscribir a normas y políticas como motivo para hacer uso de ellos.

Por otra parte, se indagó acerca de la pertinencia de los motivos por los cuales los periodistas emplean préstamos en sus textos. Para ello, se 
consideraron resultados de estudios anteriores y se les entregó una lista de motivos que ellos debían clasificar como 'totalmente pertinente', 'muy pertinente', 'relativamente pertinente', 'poco pertinente' o 'nada pertinente'.

En primer lugar, se observó que la mayoría de los motivos fueron clasificados como 'muy pertinentes' y estos apuntan a distintos aspectos: a) uso extendido del préstamo en una lengua ('por moda' y 'por contacto entre lenguas'), lo que probablemente se deba a una multiplicidad de factores como el modelo de economía abierta de Chile, la fuerte presencia del estilo de vida estadounidense que se evidencia a través de la cultura del entretenimiento, entre otros; b) uso de terminología propia de un área especializada y vacíos denominativos ('por mayor precisión léxica'), lo que posiblemente obedezca a los avances científico-tecnológicos y de la economía; c) estilo del texto o del autor y la relación de este último con el lenguaje y con el lector ('por economía lingüística', 'por causar impacto periodístico', 'por razones de estilo o de mayor efectividad en la comunicación' y 'por un propósito aclaratorio de una palabra'), lo que concuerda con lo señalado por Estornell Pons (2012), quien plantea que el uso de neologismos refleja la intención del autor de dar al discurso un estilo moderno, original e internacional, además de presentar la información de manera amena. Sin embargo, como señala Del Pino Romero (2013), a veces por desconocimiento, los periodistas introducen en la lengua múltiples calcos a través de traducciones aproximativas. Estas traducciones insidiosas pocas veces son detectadas por estos profesionales de la prensa o por los destinatarios, que no tienen un conocimiento sólido de la lengua extranjera, razón por la cual favorecerían la divulgación y la instalación del uso de estos fenómenos léxicos.

Otro de los motivos considerados como 'muy pertinente' fue 'por desconocimiento de una palabra equivalente en español'. Llama la atención, sin embargo, la clasificación de este motivo en esta categoría debido a que, como señala Hurtado González (2001: §2), "el periodista es un 'hablante de calidad' al que se le supone una sólida formación lingüística y una amplia competencia de la lengua". No obstante, la vertiginosidad de los cambios actuales da pie a innumerables voces nuevas, lo que dificulta la actualización léxico-terminológica del profesional de la prensa.

En segundo lugar, entre los motivos que los periodistas consideraron 'totalmente pertinentes' se encuentran 'por aceptación de la palabra extranjera en español' y 'porque no existe la palabra en español'. Esto confirma lo que se ha observado en estudios anteriores sobre los motivos principales por los que se utilizan préstamos de otras lenguas. Por una parte, la influencia de la lengua extranjera y el uso generalizado de algunos préstamos, y, por otra, los vacíos léxicos, es decir, la necesidad de denominar algo para lo que no existe una palabra en español (Seco 2000; González 2003; Guerrero Ramos 2010; 
Gerding et al. 2012). Además, como se observó anteriormente, estos dos motivos fueron los más frecuentes entre los que esgrimieron los periodistas para justificar el uso de voces provenientes de otras lenguas. Los motivos mencionados probablemente respondan al dinamismo natural de la lengua y a la necesidad de actualización por parte del periodista con respecto a los fenómenos que suceden en su entorno.

En tercer lugar, la 'urgencia al traducir' fue considerada un motivo 'poco pertinente'. Este resultado llama la atención debido a que esta ha sido una de las razones esgrimidas con frecuencia en estudios anteriores para explicar el uso de préstamos y de neologismos en general en el español. Por ejemplo, Ortega Martín (2001: §4) señala que "el periodista redacta su artículo [...] en un corto espacio de tiempo; por esta razón emplea mecanismos que apuestan por una expresión clara, concisa (evitando la redundancia), pues debe obtener que la comunicación con el lector se establezca rápida y eficazmente". A su vez, Méndez (2011b: §1) sostiene que "la urgencia del lenguaje que sufren provoca que los periodistas empleen todos los recursos a su mano, aunque algunos nos gusten menos que otros, y eso conlleva la aparición, en numerosas ocasiones, de verdaderos tesoros léxicos". Esta discrepancia podría deberse a que el periodista no tiene conciencia cierta de que las traducciones aceleradas pueden inducir a fenómenos como la interferencia lingüística, que se puede plasmar en la lengua meta en forma de préstamos superfluos y calcos léxicos o semánticos.

Por último, se observó una opinión dividida en tres de los motivos: a) 'como indicador de prestigio social', considerado casi de igual manera como 'totalmente pertinente', 'relativamente pertinente' y 'nada pertinente', lo que muestra una visión subjetiva por parte de los periodistas con respecto a lo que se considera prestigioso; b) 'por seguir el manual de estilo de la empresa', considerado en su mayoría como 'relativamente pertinente', lo que podría explicarse, en parte, con los resultados obtenidos en un estudio anterior (Gerding et al. 2018), que mostraron que a la mayoría de los periodistas no se les imponen limitaciones en los medios para los cuales trabajan; c) 'para moderar el significado de una palabra existente en español', considerado tanto 'muy pertinente' como 'poco pertinente', probablemente debido a que, en algunos casos, el préstamo goza de gran aceptación, mientras que el uso de su equivalente en español suele resultar perturbador para el hablante.

Finalmente, es importante señalar que los resultados sobre la pertinencia de estos motivos coinciden, de manera general, con la jerarquización de la recurrencia que se estableció en este estudio para los motivos del uso o no uso de los préstamos aducidos por los periodistas.

También se indagó acerca del uso de préstamos en secciones específicas del periódico, para lo cual se solicitó a los informantes individualizar aquellas 
en las que el uso de voces extranjeras ocurría con mayor frecuencia. Con este propósito, se les presentó una lista de secciones frecuentes de periódicos, tomando como referencia estudios anteriores de la AChN-UdeC en los que se había analizado la frecuencia de préstamos por sección del diario (Fuentes et al. 2009; Gerding y Fuentes 2011; Gerding et al. 2012a; Gerding et al. 2012b; Gerding et al. 2014). Se solicitó a los periodistas marcar un máximo de cinco opciones y, adicionalmente, se les entregó una opción de respuesta abierta para añadir alguna sección que no estuviera en la lista del cuestionario. Las respuestas de los periodistas con respecto a las secciones con la mayor frecuencia de préstamos se condice en gran medida con los resultados obtenidos en análisis anteriores realizados por la $\mathrm{AChN}-\mathrm{UdeC}$ : el $19 \%$ de los encuestados estimó que la sección Ciencia y Tecnología reunía una gran cantidad de préstamos, seguida de la sección Economía, con un $16 \%$. Otras secciones que obtuvieron porcentajes por encima del $10 \%$ fueron Internacional (13\%), Moda y Tendencias (12\%) y Deporte (11\%). Las demás opciones de respuesta (Cultura, Espectáculos, Nacional, Opinión, Portada, Reportajes, Sociedad, Otras) arrojaron porcentajes menores (ver Gráfico 1); solo Cultura y Espectáculos no coinciden con lo referido en estudios anteriores en los que se ha determinado que esta sección sí es prolífica en cuanto al uso de anglicismos.

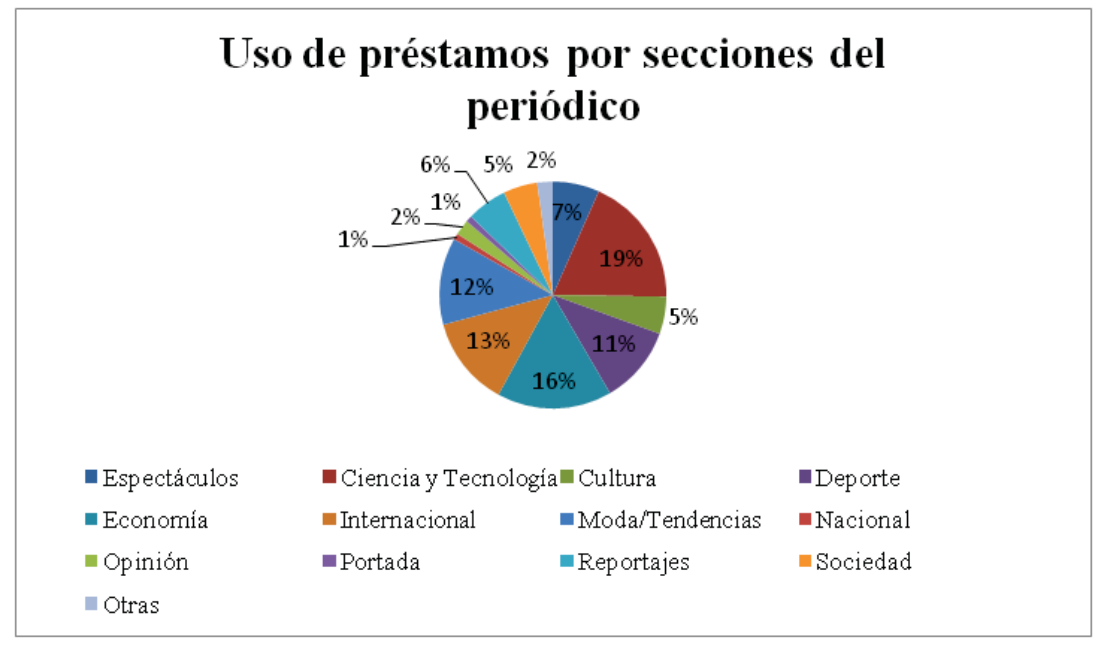

Gráfico 1. Uso de préstamos por secciones del periódico

Si se comparan estos resultados con el trabajo que realizó Gentsch (2004) sobre la base de un análisis de artículos de tres periódicos alemanes, se puede constatar que las secciones con mayor frecuencia de préstamos coinciden 
con los resultados obtenidos en el presente estudio: así, artículos sobre temas que tienen relación con la informática presentaban el más alto porcentaje de préstamos del inglés, seguidos de artículos en el ámbito de espectáculos/ sociedad, economía, fútbol y salud/bienestar. Es importante destacar que no se pueden establecer otros paralelos porque no existen estudios específicos sobre el uso de préstamos en función de las secciones del periódico.

Por otro lado, al consultárseles por el motivo del uso de préstamos en las secciones que indicaron, los periodistas nombraron diversas razones, las que se pueden agrupar en las siguientes cuatro grandes categorías: a) uso extendido de los préstamos, b) razones estilísticas y comunicativas c) exigencia terminológica y d) políticas del medio. En una quinta categoría denominada 'Otros', se agruparon motivos mencionados con menor frecuencia y para un menor número de secciones, como el uso de préstamos 'por desconocimiento de la existencia de un equivalente', 'por pereza al redactar', 'por comodidad' y 'por costumbre'.

De acuerdo con estos resultados, se puede inferir que la exigencia terminológica parece ser un motivo relevante para usar préstamos en la mayor parte de las secciones mencionadas por los periodistas, ya que se cita este motivo en 10 de las 13 secciones. Resulta interesante constatar que para las secciones de Ciencia y Tecnología, Economía, Internacional y Deporte, que según los periodistas se encuentran entre las secciones con mayor número de préstamos, se consideran relevantes los motivos de 'uso extendido' de estos, 'razones estilísticas y comunicativas' y 'exigencia terminológica', pero no así 'políticas del medio'. De las secciones más frecuentemente mencionadas, los informantes consideraron relevantes los motivos de las cuatro grandes categorías solo para las secciones de Moda y Tendencias, además de los motivos mencionados en 'Otros'.

El motivo de 'exigencia terminológica' para explicar el uso de préstamos de otras lenguas y, en particular del inglés, parece ser relevante para Gentsch (2004), quien menciona esta razón para explicar la alta presencia de préstamos del inglés en artículos de prensa alemana sobre temas de informática y economía, mientras que las razones estilísticas y comunicativas parecen ser más prevalentes en artículos sobre temáticas de espectáculos/ sociedad y salud/bienestar. En conclusión, se podría decir que, en general, existen vacíos denominativos que los periodistas llenan a través del empleo de préstamos, sobre todo en artículos de semidivulgación, y que en temas sociales existe una mayor preponderancia de motivaciones estilísticas que, desde la visión del periodista, justifican la inclusión de préstamos.

Finalmente, con el propósito de conocer la trascendencia que los periodistas le asignan a su propia responsabilidad en el proceso de incorporación de préstamos al español, se les pidió que clasificaran la 
importancia autoatribuida de su rol. En relación con esta pregunta, un 73\% de los encuestados admitió otorgar entre 'mucha' (33\%) y 'muchísima importancia' $(40 \%)$ a sus propias decisiones con respecto a estos usos, mientras que el $27 \%$ restante le atribuyó entre 'relativa' (25\%) y 'poca importancia' (2\%) a su propio papel en la incorporación de léxico de otras lenguas a su acervo, y ningún encuestado eludió su responsabilidad en este sentido (Ver Gráfico 2).

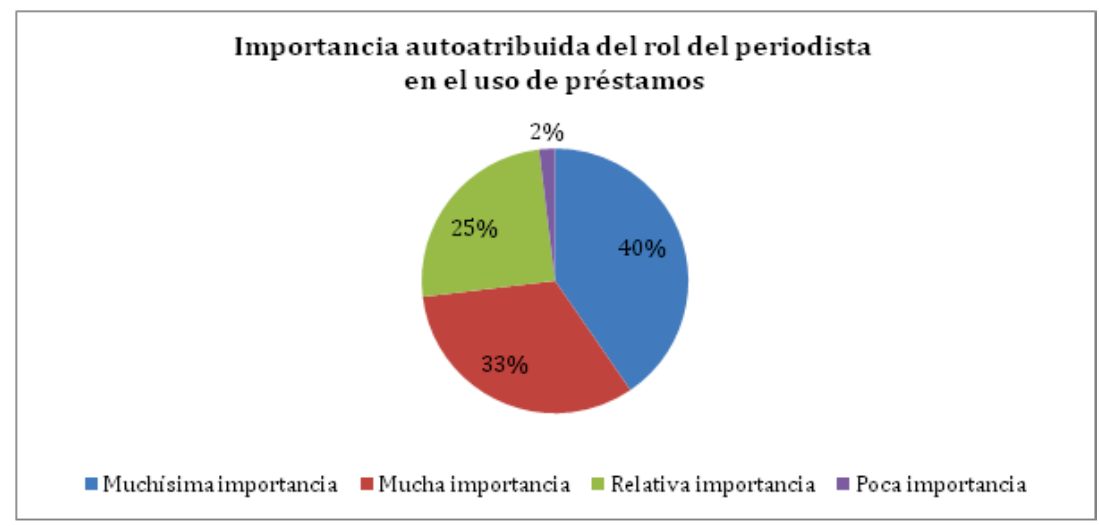

Gráfico 2. Importancia autoatribuida del rol del periodista en el uso de préstamos

No se conocen otros trabajos en los que se haya investigado acerca del rol de los periodistas en la incorporación de préstamos con consulta a los profesionales de la prensa, pero es frecuente leer opiniones de los propios periodistas con respecto al rechazo que manifiestan o la incomodidad que experimentan ante el uso de voces foráneas, particularmente de anglicismos. Por ejemplo, Federico Arango (2016), subdirector de Opinión de El Tiempo de Colombia, sostiene que los extranjerismos deben ser bien acogidos cuando se incorporan con el propósito de denominar realidades que carecen de designación en español, pero piensa que no son aceptables cuando desplazan a palabras del español que están bien consolidadas, lo que ilustra señalando que, en busca de refrescar lo viejo, hoy no se invita a comer magdalenas, sino 'muffins', y atribuye la responsabilidad de la adopción de este léxico a la publicidad. Desde esta perspectiva, los periodistas tendrían más bien la función de transmisores y divulgadores de las nuevas voces que innovadores del léxico que van incorporando de otras lenguas.

Un estudio chileno demuestra que los expertos en economía, comercio y finanzas son quienes estimulan la incorporación de léxico anglicado en la lengua en los medios masivos (Diéguez 2004), pero Gerding, Fuentes y 
Kotz (2012) sostienen que son los periodistas quienes toman la decisión de adoptar palabras y expresiones de origen anglosajón, al redactar sus crónicas, artículos, reportajes o columnas, en lugar de crear voces en español. Esta es una práctica que también se ha observado en la prensa de otras latitudes de América Latina, incluso en países en los que se usan anglicismos con frecuencia, aunque no sean proclives a la cultura estadounidense (Haensch 2005).

En cuanto al marco de referencia para la redacción, son los libros de estilo los que entregan directrices y orientaciones a los periodistas con respecto a formas, usos, preferencias, marcas, etc. Durante la formación inicial, los futuros periodistas toman conocimiento de estos cuerpos normativos. El Manual de estilo y orientaciones éticas de la Universidad Diego Portales (Chile), por ejemplo, es uno de los pocos libros de esta índole de acceso público. En él se señala que "se deben evitar las palabras en otros idiomas, salvo que no existan traducciones precisas al castellano. En estos casos, la palabra o frase debe ser escrita en cursiva" (Manual de estilo y orientaciones éticas 2014, Art. II, inciso 14). Como el peso de los libros de estilo como pautas de uso parece no gravitar fuertemente en la decisión que toma el periodista al escoger el léxico con el que construye su discurso, al menos en lo que respecta al uso de voces anglicadas, la decisión y responsabilidad del uso del léxico recaerían en los propios periodistas y en sus editores periodísticos.

A mayor abundamiento, se consultó a los periodistas encuestados acerca del motivo por el cual le asignaban determinado grado de importancia a la decisión de emplear léxico proveniente de otras lenguas. Las tres principales razones aducidas por quienes le atribuyeron 'muchísima' o 'mucha importancia' a su decisión de adoptar préstamos en la redacción de sus textos fueron: tener conciencia de la influencia que ejerce la prensa y los periodistas en los hablantes, entender el papel de los periodistas como divulgadores o propagadores de nuevas tendencias en el conocimiento y, por ende, en el léxico, y la decisión de asumir, en cierto modo, el rol de mediador intercultural con respecto a los lectores. Adicionalmente, este mismo grupo declaró que su decisión de usar préstamos tenía relevancia porque le parecía que el inglés era esencial en la comunicación actual, porque el uso de préstamos le permitía fijar ciertos estándares de uso lingüístico, porque se autoatribuía un rol de educador y de comunicador social cuya intención era "simplificar el lenguaje" y porque al usar préstamos contribuía a democratizar el uso de la lengua y a afianzar su propia credibilidad.

Por otra parte, entre las razones argüidas por los periodistas que le asignaron 'relativa importancia' a su decisión de usar préstamos en la redacción sobresale la respuesta 'no sé'. Otras razones expuestas por los 
periodistas que no le asignan gran importancia a su rol en la incorporación de préstamos en la lengua fueron que no percibían que fuera el periodista quien imponía el uso, sino la sociedad en su conjunto y que no lo hacían frecuentemente por el tipo de lenguaje que debe emplear el cronista para cumplir con su rol de comunicador social; por el deseo de lograr la mayor claridad posible en la entrega de la información; o por el hecho de no percibir al periodista como educador. Esta relativa importancia se explicaría también por la convicción respecto del rol de divulgador o propagador de nuevas tendencias que tiene el periodista y de su papel de mediador intercultural y de receptor de usos instaurados por otros profesionales, por otra.

Finalmente, quienes argumentaron a favor de la 'poca importancia' de su función en la inclusión de léxico proveniente de otras lenguas señalaron que las redes sociales están reemplazando el ejercicio profesional del periodista, con lo que se supone que el léxico de origen extranjero ingresa con menos filtros o sin ellos.

Se presume que los periodistas tienen (o deberían tener) clara conciencia de la responsabilidad que recae sobre ellos respecto tanto del contenido como de la forma de sus palabras. Siguiendo este principio de la formación periodística, entonces, necesariamente deberían estar conscientes de la importancia de sus roles, por cuanto sus discursos, en la forma y el fondo, pueden crear opinión pública, guiar tendencias y configurar modelos de comportamiento y modos de expresión.

La mayoría de las investigaciones sobre el rol del periodista se centra en su condición de comunicador y en la efectividad, la veracidad y la credibilidad de la comunicación. Un número reducido de estudios ha abordado las nuevas formas discursivas en la prensa con diversos enfoques (por ejemplo, estudios de prensa y género, Estornell Pons 2012; Cañete González 2016), pero no con base en la redefinición del rol del periodista como mediador entre los acontecimientos de los nuevos tiempos y el público general. En efecto, la responsabilidad que comparten los periodistas con los usuarios con respecto a la innovación del léxico ha tenido hasta ahora poca discusión.

\section{CONCLUSIONES}

Desde la observación, los investigadores del presente trabajo estiman que la premura al redactar sería uno de los factores que conducen a algunos periodistas a incorporar unidades léxicas extranjeras, especialmente desde 
el inglés. Sin embargo, los profesionales de la prensa consideran este motivo 'poco pertinente', lo que, de algún modo, se podría interpretar como elusión por parte de ellos en lo que respecta a su participación en esta forma de ampliación del acervo léxico.

Con estos resultados se confirma que, en determinadas secciones, los periodistas usan más préstamos y lo hacen con el propósito de cubrir ciertas necesidades lingüístico-culturales; por ejemplo, en Informática y Economía la necesidad es principalmente terminológica, mientras que en temas sociales como Espectáculos, Sociedad, Salud y Bienestar, las motivaciones que justifican la inclusión de préstamos son más bien estilísticas.

En cuanto a las razones que guían a los periodistas a usar préstamos, el llenar un vacío léxico o cultural y el uso extendido de la unidad léxica extranjera son los motivos que aducen con más frecuencia. De este modo, se estaría en presencia de un fenómeno de transculturación, propio de los tiempos de globalización que viven algunas sociedades actuales.

Entre las razones que los periodistas esgrimen con menos frecuencia están las estilísticas y comunicativas y los vacíos terminológicos. Si bien el uso de préstamos por estos motivos es moderado, la intención que aduce el periodista es, por una parte, establecer una comunicación más cercana con el lector replicando voces extranjeras que el hablante ya maneja y, por otra, lograr una mayor precisión al usar el término extranjero.

Finalmente, en este trabajo no se ha podido determinar si la incorporación de préstamos en el español es una responsabilidad individual o compartida, es decir, si los periodistas recogen y divulgan las voces extranjeras que circulan en la comunidad de hablantes o si es esta comunidad la que las introduce en el acervo lingüístico. Aparentemente, ambas partes se estarían retroalimentando de forma permanente. Sin embargo, se observa una falta de correspondencia entre lo que estos profesionales afirman y la abundancia de préstamos en las reseñas noticiosas.

Al reflexionar acerca de los resultados y conclusiones del presente trabajo, se plantea la posibilidad de futuras investigaciones en las que se indague acerca de cómo la rapidez de las comunicaciones puede influir en la actualización léxico-terminológica de los periodistas. Por otra parte, sería interesante investigar si el ingreso del léxico extranjero al español a través de las redes sociales afecta la capacidad de los profesionales de la prensa para filtrar las voces extranjeras, ya que estos medios representan un tamiz menos riguroso que favorece el uso inconsciente de préstamos. 


\section{REFERENCIAS BIBLIOGRÁFICAS}

Alcoba Rueda, Santiago. 2007. Autorización y uso de los neologismos. En Ramón Sarmientos y Fernando Vilches (coord.). Neologismos y sociedad del conocimiento. Funciones de la lengua en la era de la globalización, pp. 23-47. Madrid/Barcelona: Fundación Telefónica/ Editorial Ariel, S.A.

Arango, Federico. 2016. "El 'oso' de usar anglicismos en la oficina para descrestar". [en línea]. Disponible en https://www.eltiempo.com/archivo/documento/CMS-16509558 [Consulta 7/07/2017].

BARBero Andrés, JaVIer. 2010. El español de los negocios y el inglés: convergencias y divergencias. Ponencia presentada en el XX Congreso Internacional de la Asociación para la Enseñanza del Español como Lengua Extranjera (ASELE). Cantabria, España. Disponible en https://cvc.cervantes.es/ensenanza/biblioteca_ele/asele/pdf/20/20_0269. pdf [Consulta 10/12/2018]

Bernal-Meza, Raúl. 2008. Argentina y Brasil en la política internacional: Regionalismo y Mercosur (estrategias, cooperación y factores de tensión). Revista Brasileira de Politica Internacional 51(2): 154-178.

Briceño Ruiz, José. 2006. Regionalismo estratégico en las relaciones de la Unión Europea con América del Sur. Comercio Exterior 56(5): 428-434.

BoUWMAN, JANKE A.J. 2017. Los anglicismos léxicos en el español peninsular actual: norma y uso. Tesis para optar al grado de Master en Spanish Linguistics, Radboud University Nijmegen. Disponible en https://theses.ubn.ru.nl/bitstream/handle/123456789/4969/ Bouwman\%2C_Janke_A.J._1.pdf?sequence $=1$ [Consulta 10/12/2018]

Cabré, María Teresa. 1989. La neologia efimera. En Joan Bastardas (ed.). Estudis de Llengua i Literatura Catalanes XVIII, pp. 359-376. Barcelona: Publicacions de l'Abadia de Montserrat.

CAÑete GonzÁlez, Paola. 2016. Innovación léxica y género en textos periodísticos del español actual. Tesis para optar al grado de Doctor en Comunicación Lingüística y Mediación Multilingüe, Universitat Pompeu Fabra.

Cea Egaña, José Luis. 1985. Régimen jurídico vigente para el ejercicio del periodismo en Chile. Cuadernos de Información, 2, 47-95.

Chela-Flores, Godsuno. 1998. Orígenes y estado actual del español de Venezuela. Caracas: Comisión Regional Macuro 500 años.

Chumaceiro, Irma y Alexandra Álvarez. 2004. El español, lengua de América. Caracas: El Nacional.

Delgado Álvarez, Alberto. 2005. Los anglicismos en la prensa escrita costarricense. Káñina 29 (Número especial), pp. 89-99.

Del Pino Romero, Javier. 2013. Influencia del inglés sobre cuatro lenguas europeas: anglicismos crudos y semánticos en francés, italiano, neerlandés y ruso. Tesis para optar al grado de doctor en Traducción, Universidad de Valladolid.

DiÉguez, María Isabel. 2004. El anglicismo léxico en el discurso económico de divulgación científica del español de Chile. Onomázein 10: 117-141.

2005. Análisis contrastivo del anglicismo léxico en el discurso económico semiespecializado y de divulgación científica del español de chile. Onomázein 12.2: $129-156$.

El País. 2005. Diccionario de dudas. [en línea]. Disponible en https://elpais.com/ diario/2005/12/04/opinion/1133650808_850215.html [Consulta 10/12/2018] 
Escuela de Periodismo, Facultad de Comunicación y Letras, Universidad Diego Portales. 2014. Manual de estilo y orientaciones éticas [en línea]. Disponible en: http://comunicacionyletras.udp.cl/periodismo/wp-content/uploads/2015/04/ ManualEstilosPeriodismo.pdf [Consulta 17/12/2018]

Esteban Asencio, Laura. 2008. Neologismo y prensa. Anmal Electrónica 25: 145-165.

Estornell Pons, María. 2012. Préstamos del inglés en revistas femeninas: entre la necesidad denominativa y la estrategia pragmática. Pragmalingüística 20: 61-91.

Fuentes, Mary, Constanza Gerding, Alma Pecchi, Gabriela Kotz y Paola Cañete. 2009. Neología léxica: reflejo de la vitalidad del español de Chile. RLA Revista de Lingüística Teórica y Aplicada, 47(1): 103-124.

Gentsch, KeRstin. 2004. English Borrowings in German Newspaper Language: Motivations, Frequencies, and Types, on the basis of the Frankfurter Allgemeine Zeitung, Muenchner Merkur, and Bild. Tesis para optar al grado de Bachelor of Arts, Swarthmore College.

Gerding Salas, Constanza, Paola Cañete González y Carolin Adam. 2018. Neología sintagmática anglicada en español: Calcos y préstamos. Revista Signos, Vol. 51, № 97.

Gerding, Constanza, Mary Fuentes y Gabriela Kotz. 2012a. Anglicismos y aculturación en la sociedad chilena. Onomázein, 25(1): 139-162.

Gerding, Constanza, Mary Fuentes, Lilian Gómez y Gabriela Kotz. 2012b. El préstamo en seis variedades geolectales del español: Un estudio en prensa escrita. Revista Signos. Estudios de Lingüística 40(80): 281-299.

Gerding, Constanza y Mary Fuentes. 2011. Loanwords in the Press: The Influence of English in Chile. "XIX FIT World Conference". San Francisco, Estados Unidos.

Gerding-Salas, Constanza, Mary Fuentes, Lilian Gómez y Gabriela Kotz. 2014. Anglicisms: An active word-formation mechanism in Spanish. Colombian Applied Linguistics Journal 16(1): 40-54.

Gerding Salas, Constanza, Paola Cañete González y Carolin Adam. 2018. Periodistas: ¿usar o no usar préstamos? he ahí la cuestión. Nueva Revista del Pacífico 68: 42-61.

González Rodríguez, Gustavo. 2003. 50 años de periodismo universitario en Chile. Comunicación y Medios 14: 7-16.

González, María Isabel y María Jesús Rodríguez. 2011. La función pragmática de los anglicismos: algunos ejemplos en el habla juvenil de Las Palmas de Gran Canaria. Miscelánea. A Journal of English and American Studies 43: 13-31.

GonzÁlez, María Isabel. 2003. Anglicismos innecesarios en el habla culta de Las Palmas de Gran Canaria. EPOS, XIX: 193-218.

Guerrero Ramos, Gloria. 2010. Neologismos en el español actual (3 $3^{\mathrm{a}}$ ed.). Madrid: Arco Libros.

Guerrero Ramos, Gloria. 2013. El préstamo lingüístico, uno de los principales procedimientos de creación neológica. Quaderns de Filologia. Estudis lingüístics 18: 115-130.

HaEnsch, Günther, 2005. Anglicismos en el español de América. Revista ELUA. Estudios de Lingüistica 19: 243-251.

Hurtado GonzÁlez, Silvia. 2001. Los periodistas y la lengua. En Actas del Congreso "Vigencia del periodismo escrito en el entorno digital multimedia". [en línea] Disponible en: http:// webs.ucm.es/info/perioI/Period_I/EMP/Numer_07/7-5-Inve/7-5-08.htm [Consulta $17 / 12 / 2018]$

Ley 12.045. Diario Oficial de la República Chile, Santiago, Chile, 11 de julio de 1956.

Llopart-Saumell, Elisabet y Judit Freixa. 2014. La función comunicativa de los neologismos: caracterización a partir de criterios basados en el uso. En Alan Floyd (ed.). Proceedings of the 12th Conference of the European Association of Specific Purposes (AELFE), pp. 240-251. A Coruña: Galebook.

Martínez Otero, Rutilio. 1959. Cultismos. Archivum IX: 189-215. 
Mellado Ruiz, Claudia y Carlos del Valle Rojas. 2008. Diagnóstico y perspectivas del periodismo como profesión: Reflexiones en torno a la formación de los profesionales de la comunicación en Chile. Revista Universum 23(2): 136-151.

Méndez, María del CARMen. 2011a. Los neologismos morfológicos del español en el lenguaje de la prensa. Sarrebruck: Académica Española.

2011b. De cómo los neologismos enriquecen la lengua. Río Negro. [en línea]. Disponible en: https://www.rionegro.com.ar/cultura-show/de-como-los-neologismosenriquecen-la-lengua-MQRN_767496 [Consulta 17/12/2018].

Morin, Regina. 2006. Evidence in the Spanish language press of linguistic borrowings of computer and Internet-related terms. Spanish in Context 3(2): 161-179.

ObServatori de Neologia. 2004. Metodología de trabajo en neología: criterios, materiales y procesos. Papers de l'IULA. Serie Monografies 9. Barcelona: Universitat Pompeu Fabra. Institut Universitari de Lingüística Aplicada.

Ortega Martín, María Pilar. 2001. Neología y prensa: un binomio eficaz. Espéculo 18. [en línea]. Disponible en: https://webs.ucm.es/info/especulo/numero18/neologism.html [Consulta 17/12/2018].

Otaola Olano, Concepción. 2004. Lexicología y Semántica léxica. Madrid: Ediciones Académicas.

Perdiguero, Hermógenes. 2003. Innovación léxica en la prensa. En Hermógenes Perdiguero y Antonio A. Álvarez (eds.). Actas del XIV Congreso internacional de ASELE, pp. 88-95. Burgos: Servicio de Publicaciones Universidad de Burgos.

Pérez lagos, Manuel Fernando y Gloria Guerrero Ramos. 2005. Renovación léxica y Diccionario: el nuevo "Moliner". ELUA. Estudios de Lingüística 19: 193-222.

Real Academia Española. 2018. Tratamiento de los extranjerismos [en línea]. Disponible en: http://www.rae.es/diccionario-panhispanico-de-dudas/que-contiene/tratamiento-delos-extranjerismos [Consulta 17/12/2018].

RondeAu, GuY. 1983. Introduction à la terminologie. Québec: Gaëtan Morin Éditeur.

SÁez Godoy, Leopoldo. 2005. Anglicismos en el español de Chile. Atenea 492: 171-177.

SÁiz Martínez, Fernando. 2011. El lenguaje en el periodismo económico, o cómo no gatillar el repo [en línea]. Disponible en: http://congresosdelalengua.es/valladolid/ponencias/ el_espanol_en_la_sociedad/1_la prensa_en_espanol/saiz_f.htm [Consulta 17/12/2018].

Seco, Manuel. 2000. La importación léxica y la unidad del idioma: anglicismos en Chile y en España. Boletín de Filología 38(1): 253-280.

SuRvey Monkey®. 2018. Programa que permite la creación de encuestas en línea, Versión 7. San Mateo, California [en línea]. Disponible en: https://www.surveymonkey.com [Consulta 17/12/2018].

Vélez Barreiro, Marco. 2003. Anglicismos en la prensa económica española. Tesis para optar al grado de Doctor en Estudios Lingüísticos, Universidade da Coruña.

Zerán Chelech, Faride. 2003. Discurso 50 años Escuela de Periodismo Universidad de Chile. Comunicación y Medios 14: 86-90. 